\title{
Mapping of Illegal Dumps in the Czech Republic - Using a Crowd-Sourcing Approach
}

\author{
Miroslav Kubásek \\ EnviWeb s.r.o., Březová 352/6, 63700 Brno, Czech Republic \\ miroslav.kubasek@enviweb.cz
}

\begin{abstract}
The paper describes an environmental project ZmapujTo (www.ZmapujTo.cz) which is intended to fight against illegal waste dumps in the Czech Republic using a modern, effective and widespread platform. As a supporting tool a smartphone/tablet reporting application ZmapujTo has been developed. This freely available mobile application enables users to report illegal dumps and also overloaded of municipal waste containers. The project ZmapujTo is intended for all people who want to live in a clean environment in their cities, villages or countryside and additionally want to raise awareness of unacceptable environmental behaviour of people.

Users of this GIS based mobile application can report illegal dumps quickly and easily by using their smartphones/tablets. Thus, everybody can use this interactive public web form to report illegal dumps in the Czech Republic. The objective of this project is to contribute to reduce environmental pollution caused by illegal dumps in the Czech Republic by making available a modern, effective and widespread platform for reporting and monitoring of illegal dumps.
\end{abstract}

Keywords: illegal dumps, mapping, reporting, GPS, mobile application, crowd-sourcing.

\section{Introduction}

Illegal dump sites have always been a trouble endangering not only local environment but also human health. It is estimated that currently 100 million tons of illegally waste is dumped world-wide [1].Therefore, people should not be indifferent to that and report to competent and responsible authorities if they find an illegal dump site in order to take actions. The illegal trafficking and dumping of waste heavly affects our environmental, economy and human well being. The costs for cleaning-up illegal dump sites are extremely high, especially if this involves multiple countries. For example, approximately 134,000 tons of waste was illegally dumped in a large gravel pit in North East Europe and the extraction and transport of this waste costs 160 Euros per ton which added up to over 21 million Euros. It is even more costly when the waste is considered to be hazardous. The cost rises to about 300 Euros or more per ton [2]. 
For example, the situation in United Kingdom is monitored by councils across England to reveal their illegal dumping statistics, to compare relative performance, and to identify opportunities for improvement. In 2012, 732,052 illegal dumps on public land have been reported, 9.1\% less compared to previous year $(805,320)$ according to the AnyJunk Fly Tipping Report 2012 [3]. £33m have been spent by the councils on illegal dumping clearance; but only $0.6 \%$ of illegal dumping incidents were successfully prosecuted.

During the last decade, in the Czech Republic, several thousand cases of illegal dumping have been reported. For example, the average amount of accumulated waste in the years 2007 to 2009, put to illegal dumps in the forests was about 8 thousand $\mathrm{m}^{3}$. The average annual area coverd by illegal dumps for example in the forests is approximately 3,4 hectares and 250 tons. The average annual disposal costs for waste from illegal dumps in the forest is about 40 thousand Euros. In 2010, it 830 illegal dumps have been registered in the forests of the Czech Republic, their total area reaches almost 5,4 hectares with 280 tons of waste. Disposal costs exceeded 40 thousand Euros [4].

An even worse situation is the illegal dumping of waste in municipallity areas in the Czech Republic. In 20011130 thousand tons of waste have been disposed as reported by the the Waste Management Information System of the Czech Republic (2013) [5] operated by the Czech Environmental Agency (CENIA).

The cost of the disposal of illegal dumps exceeded 20 million Euros. In addition to that, it it can be assumed that many other cases of domestic illegal dumping have not been reported because of insufficient inspection. Local municipal governments confronted with such illegal dumping issues have been working hard to take countermeasures.

An important approach for environmental protection suitable for all regions is to promote the enforcement of municipal policies assuming the residents' improved awareness and deliberate participation. To understand visible changes to the environment such as illegal dumping, in particular, it is urgently needed to create a mechanism and/or tools for a close collaboration between the residents and administration in the Czech Republic.

The progress in information and communication technologies (ICT) in recent years has extended to the environment surrounding geographic information systems (GISs). These GISs are integrated into professional spatial analysis tools conventionally used by research institutes and technical consultants up to familiar information utilization tools using general PCs in USA [1], Japan[6-8] and Australia. The Regional Illegal Dumping Database in Illegal Dumping project is being managed by Hunter and Central Coast region in New South Wales [9] to compare and analyse data collected by councils, from dumping sites. All incidents are entered into a database, which is linked to a GIS that is able to produce locations' maps for each council area.

The "e-japan" Strategy formulated by the Japanese Government in 2001 advocates the introduction of ICT to the administration, aiming at the establishment of an infrastructure for the world's most advanced communications environment by 2005. "GIS Action Program 2002-2005" based on the e-japan Strategy includes the plan for effec- 
tively using GISs in various governmental fields to streamline administration and to provide higher-quality administrative services [7].

"Let's do it 2008" project was a campaign that began in Estonia that was led by one of the inventors of Skype - Ahti Heinla and the founder of Microlink and Delfi- Rainer Nolvak. They put cutting-edge ICT and 40,000 volunteers to work Saturday to clean-up the tiny Baltic Sea state of Estonia. Heinla and Nolvak used special software based on Google Earth, positioning software for mobile phones and mobile phones with GPS to map and take images of illegal garbage dumps across the country. The innovative software also brings the massive garbage collection campaign virtually into living rooms where Estonians can follow its real-time progress, organisers said. The project aims to recycle 80 percent of the estimated 10,000 tonnes of garbage in illegal dumps ${ }^{1}$.

The European Commission has supported the EuropeAid Project "Waste Governance - European neighbourhood and partnership instrument (ENPI) East" (Azerbaijan, Armenia, Belarus, Georgia, Moldova, Russia, and Ukraine) with "Completed Pilot Region Inventories of Existing Illegal/Non-Compliant Disposal Sites"2. One key sub-result whose achievement will ultimately lead to the achievement of the main result is the development of an existing register of illegal waste disposal sites through, firstly, a desk-based review of the existing inventory and then it's updating through a series of field visits and stakeholder consultation throughout the pilot region.

\subsection{Utilization of ICT in Dealing with Environmental Issues}

A Ddescription of ICT related projects in the area of environmental respectively waste problems in the Visegrad countries are published in the report "Visegrad Countries: Environmental Problems and Policies" [10]. Authors are describing good and bad practices of ICT technology utilization. On the base of existing social and environment-related systems operating in the Visegrad countries region the report concluded, that several crucial common problems exist. Such as:

Poor visibility - the most common and very serious disadvantage. Reporting systems are not advertised properly, thus people do not know that they can use them.

Poor or even lack of internationalization - reporting systems are usually provided in one local language either translated partially or incorrectly. Lack of translation into a commonly recognized international language (e.g., English) makes it difficult or even impossible for foreigners to find such a system and/or use it.

Limited scope - many systems have been built to serve only one particular purpose or to help in solving problems of problems only of small regions. Some of them are discontinued after having solved the problem.

Lack of integration with other systems - systems shows almost no traces of integration with other systems, especially with systems funded by the government.

\footnotetext{
1 Map of the garbage dumps can be seen at:

http: / / www . teeme2008 . ee / ?op=body=55ar / mas

2 See web site http: / / www . wastegovernance.org/index_eng.html
} 
These general problems pointed out in this analyse should be taken into account when preparing or extending social system dealing with reporting of environmental issues.

\section{Project ZmapujTo}

The project ZmapujTo ${ }^{3}$ dealing with the mapping illegal dump sites was started in the middle of 2011, the web site (http://www.ZmapujTo.cz) have been put in operation during summer 2012. The initial aim of the project was to motivate citizens to start creating a map of illegal dump sites in their surroundings

At the end of 2012 we put the administrative part of the system for municipalities into operation and we tested its functionality in different pilot territories. The administration function has been fully operational in May 2013 and we are now trying to involve as many municipalities, town districts and other organizations responsible for disposal of illegal dump sites as possible.

The main aim of this project is the possibility to inform the public on the issue and economic drawbacks of illegal dump sites. The project also envisages a more efficient use of municipality finance resources used for the disposal of dump sites; furthermore it will also contribute to catch the illegal waste dumping people or companies. ers.; and finally, it will contribute to their prevention.

An active involvement the administration of municipalities in the project has many advantages. The municipality makes the citizens aware that it takes the issue of illegal dump sites serious and it also saves its expenses of dedecting new dump sites in its territory. Moreover, a timely dedection of a new illegal dump site reduces the expenses of its disposal. The GIS application allows for an easy observation of the sites even in difficult terrains, including the plot number and the owner. An appropriate municipal authority can thus gain maximum information about the illegal dump site without seeing the site personally.

Timely disposed illegal dump sites can also prevent environmental impact and damage to a larger extent (soil and water contamination, hazard of fire etc.), it improves the safety of human health, provides prevention of possible injuries (children, animals etc,), and prevents further uncontrollable extension of illegal dump sites (see Figure 1).

To enable a detailed viewing of reported illegal dumps and their surrounding areas we have included into an interactive map several advanced GIS technologies. The first one is the Google Street View, which enable users to get a very detail overview of the situation around the illegal dump. Google Street View is a feature of Google Maps that provides $360^{\circ}$ panoramic street-level views and allows users to view parts of selected cities and their surrounding metropolitan areas at ground level. Google Street View displays photos that have been previously taken by a camera mounted on a car, and can be navigated using either the arrow keys on the keyboard or by using the mouse to click on arrows displayed on the screen. Using these devices, the photos can be viewed in different sizes, from any direction, and from a variety of angles ${ }^{4}$.

3 English equivalent of Czech words "Zmapuj To" is "Map It".

4 Source: http://en.wikipedia.org/wiki/Google_Street_View 
Panoramio is the second feature, which enables geolocation-oriented photo sharing. The goal is to allow users to learn more about a given area by viewing the photos that other users have taken at that place ${ }^{5}$.

Next feature enables the integration of a cadastral map of the Czech Republic ${ }^{6}$. This feature can simply identify an owner of a specific plot so that the municipal officer can directly contact the owner.

This interactive map is also enhancement by a set of layers that enable users to adjust the map according to their needs. A user can select from an ortofoto layer either displaying satellite images, hybrid layers or displaying a mixture of normal and satellite views and terrain layers or displaying a physical map based on terrain information. Furthermore the map can also integrate three-part map layers e.g. Bing maps, Yahoo maps or Open Street maps. The interactive map also integrates a heat map (graphical representation of data where the individual values contained in a matrix are represented as colours). This heat map enables visualizing the frequency of illegal dumping.

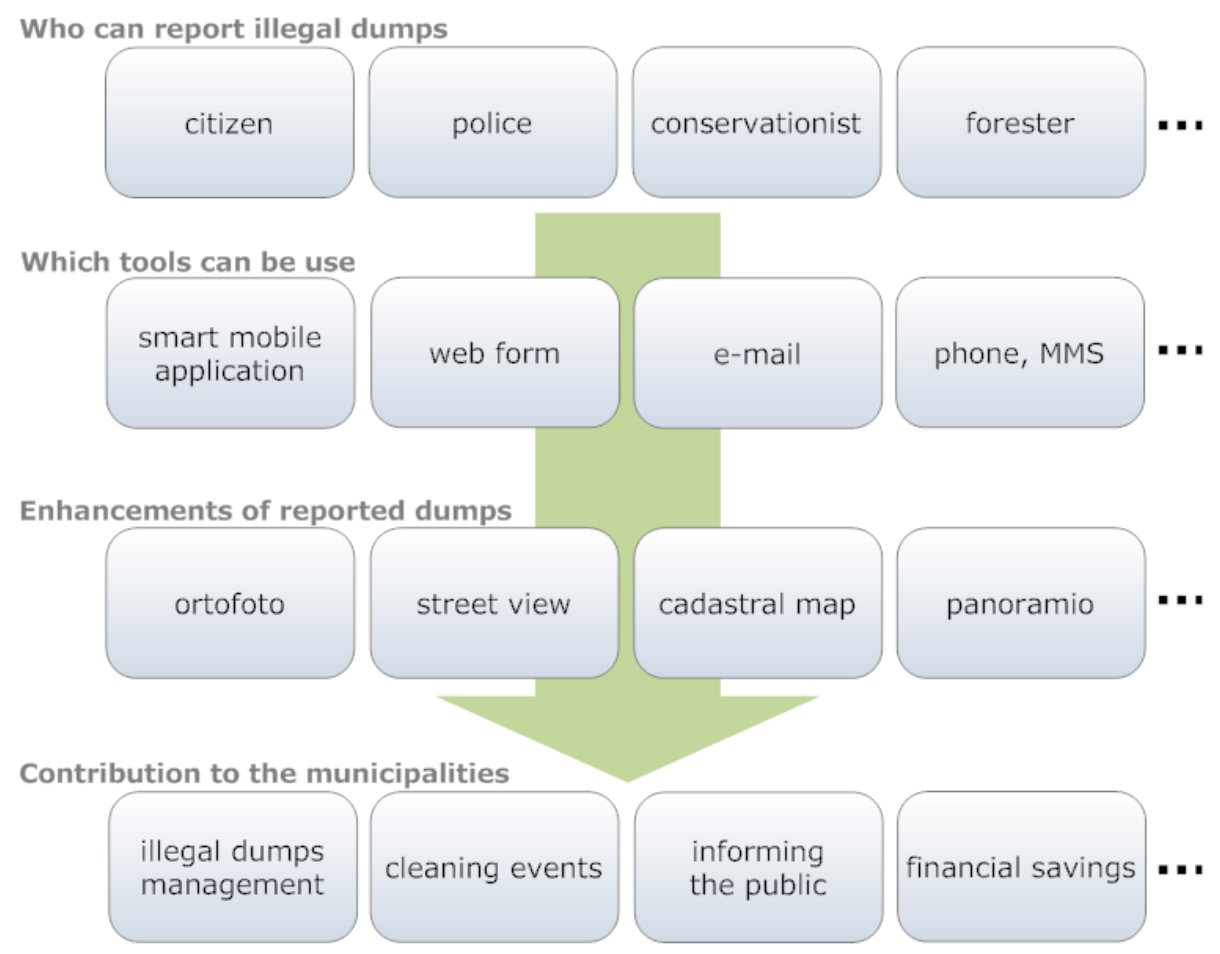

Fig. 1. ZmapujTo approach

\footnotetext{
5 Panoramio is reachable under web address http: / /www . panoramio.com

6 See http: //nahlizenidokn.cuzk.cz/
} 
Thanks to the linkage of the project ZmapujTo to local governments of the Czech Republic as well as to forest owners, PLA administrators, etc., the person who owns the specific site can quickly react and take action.

The ZmapujTo project also aims to inform the public about the dangers related to illegal dump sites, motivate the public to report dump sites, but also offers municipalities and other organizations a tool for administration of all these reports.

\subsection{Reporting Tools}

The primary way of sending reports about illegal dump sites is by using the mobile phone application ZmapujTo. Currently, this application is available Android and iPhone operating systems and everybody can download it from the project web site or via Google Play ${ }^{7}$ and Apple iTunes ${ }^{8}$.

The user can take a photo of an illegal dump site with his smart phone and marks its exact location in a map. The GPS in the smart phone determines the position approximately and the user can then change it so that it fits the reality. Then the user selects the size of an illegal dump site, specifies what type of waste is there and sends the report (Figure 2).
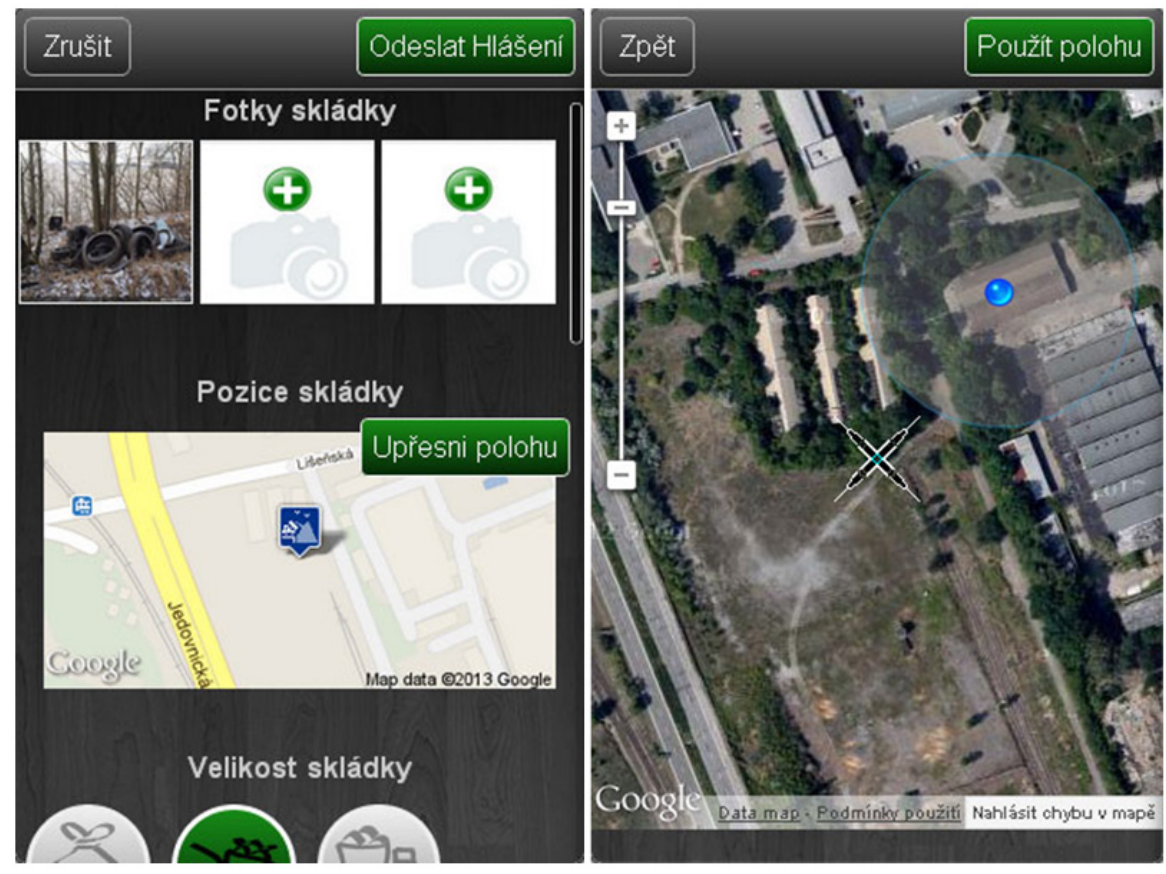

Fig. 2. Screenshot of the mobile device application

\footnotetext{
https: / /play.google.com/

8 https://itunes.apple.com
} 
All reports are anonymous, but the user can also insert optionally a comment or his contact data. After checking if the report is genuine (elimination of spam or experimental/erroneous reports), all reports are displayed in the interactive map at the web site and the related municipalities can use this information to take actions.

Alternatively, the user can use the web interactive form to report an illegal dump site. The interactive form can be opened in a computer with a common web browser, or in a mobile device (smartphone, tablet). The address for the web browser is http://new.zmapujto.cz.

\subsection{Interactive Map}

After the mentioned verification of reports, all reported illegal dump sites appear in an interactive map, available at web address http://skladky.zmapujto.cz (Figure 3.). This map allows filterning for new reports, reports about to be removed or the already removed dump sites. At the bottom part of the interactive map a list of the latest reported illegal dump sites is displayed. The map has also a function that can show a list of the dump sites closest to a selected location, including information about the distance from/to the site.

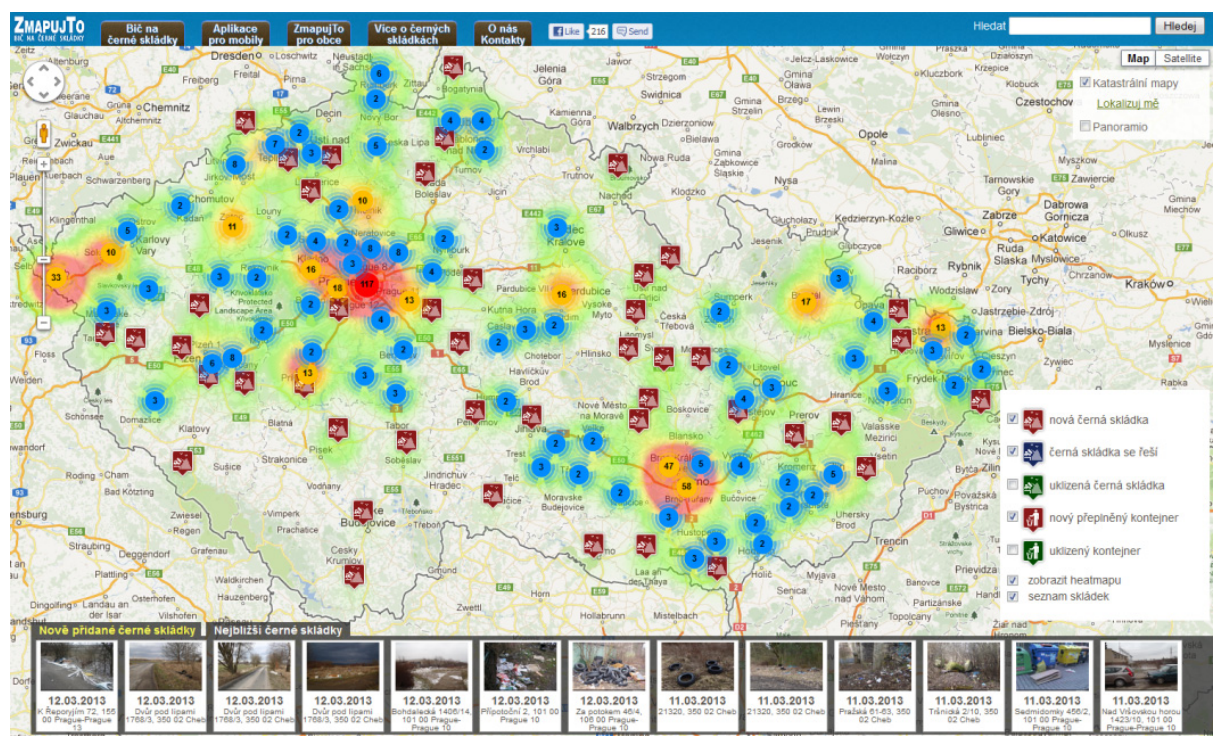

Fig. 3. Print screen of the interactive map with illegal dump sites

The interactive map has several layers (including satellite images), as well as the map layer of the cadastre of real estates, which allows for an easy identification of the owner of related property. It is forssen that in the future, more layers can be integrated (e.g. points of waste collection, legal dump sites, contaminated places, etc.) from the Czech National Geoportal $^{9}$ using INSPIRE standards. This map is also equipped with

9 http://geoportal.gov.cz/web/ 
the Google Street View technology which allows viewing the place using panoramic photos taken in the street. Thanks to this, a user can gain a very detailed view where the illegal dump site is without even going there.

\subsection{Illegal Dumps Management}

An important part of the project is the administration and management of illegal dump sites, which allows municipalities or other interested organizations to get involved in the project. The aim of this part of application is to provide a simple tool providing information to municipalities about illegal dump sites reported in its district (Figure 4.). The administrator of the municipality allotted to a specific dump site can change its status - e.g. when they are preparing to dispose it, it has been removed, comments can be added, or reports concerning the expenses of its disposal. If a new illegal dump site appears within the district, the administration system of application sends an email to the administrator of the municipality. The administrator can also use the statistics of the district and a widget, which can be placed on the municipality web site and inform thus the visitors of the municipality web site that the municipality is involved in the project, how many dump sites have been reported, removed or what expenses have been related to its disposal.

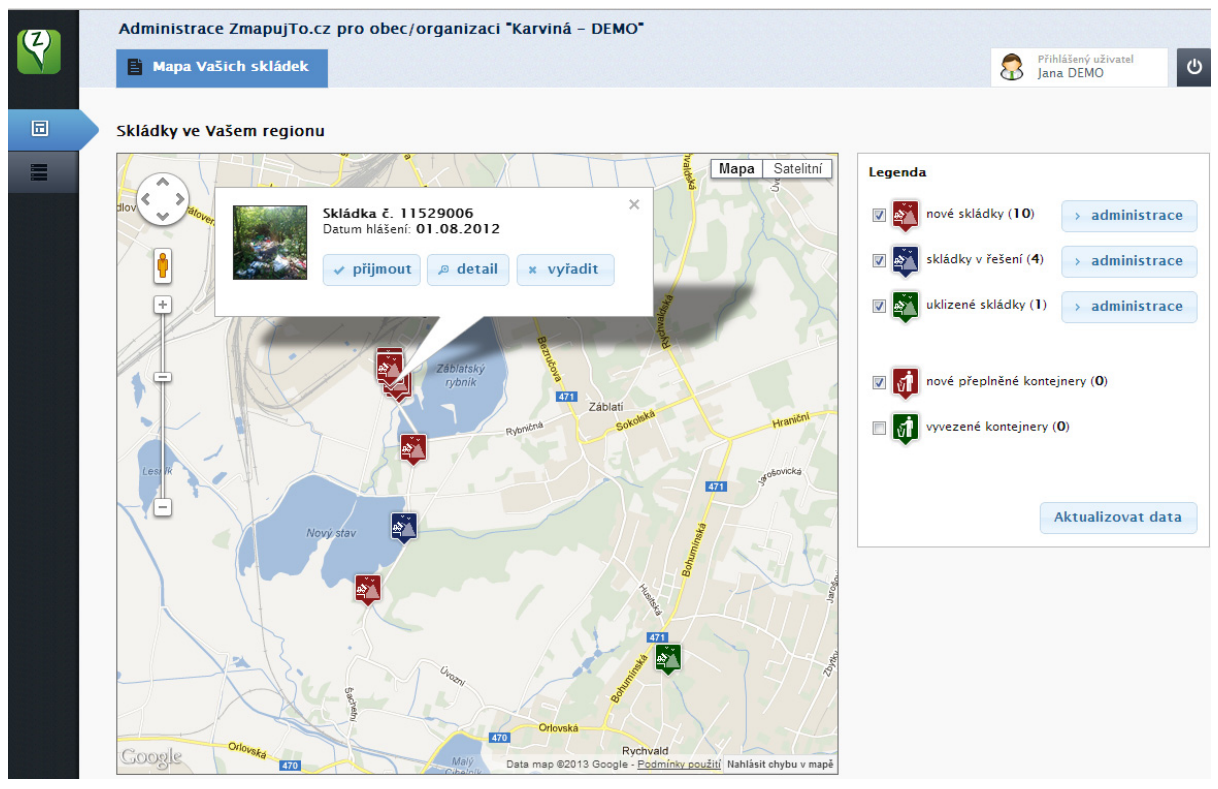

Fig. 4. Screenshot of the administration application for illegal dump sites

Currently, there are 29 municipalities and institutions from the entire Czech Republic involved in ZmapujTo project. We are collecting their experience using the information system, their comments concerning improvements and we are expanding 
the service based on these feedbacks. There is also a DEMO version of the administration application available so that a potentially interested person can try this system.

One of the most active system users are the officials of the city district Praha 10, whose are using this system intensively. They have even been able to involve city policemen, whose now report illegal dump sites and overfilled garbage bins as a part of their daily guarding walks. Within two months, there have been 371 illegal dump sites reported and 294 of them have been disposed.

\subsection{Illegal Dumps Analyse}

Since July 20121780 illegal dumps have been reported and more then 400 dumps have been cleaned (State to 15. July 2013). The Figure 5 shows the aquivalent area representation of the reported dumps. The greatest part of dumps has a medium size (44\%). Small sized dumps are illegal dumps which can be cleaned and transported by hand, the medium sized dumps are dumps up to $5 \mathrm{~m}^{3}$ and above this volume it is recognized as a big dump. The small amount of overloaded containers is due to the fact that this type of reporting has stared much later (since January 2013).

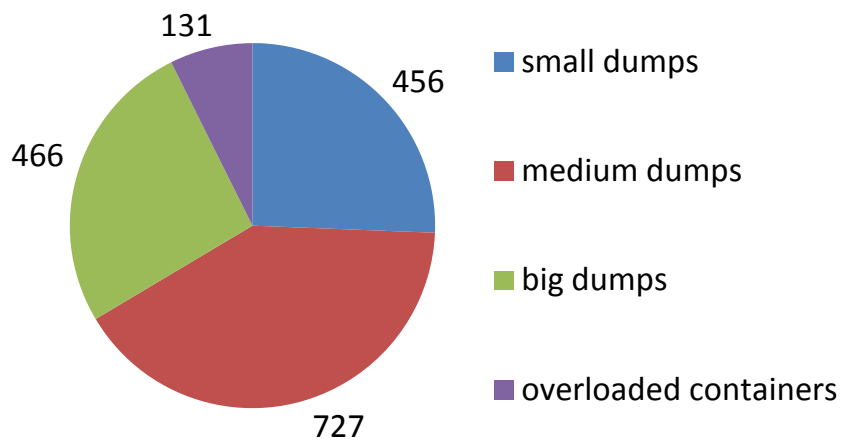

Fig. 5. Representation of illegal dumps

During the reporting process the user has to specify in more detail the waste type. The user can select from 12 waste categories which cover the whole range of possible wastes. He can assign one or more categories in one report. As can be seen in Figure 6 , the most common type of an illegal dumped waste is household waste and plastics. More than ten percent of these dumps still contains construction and demolition waste but also automotive waste (tires, batteries etc.). 


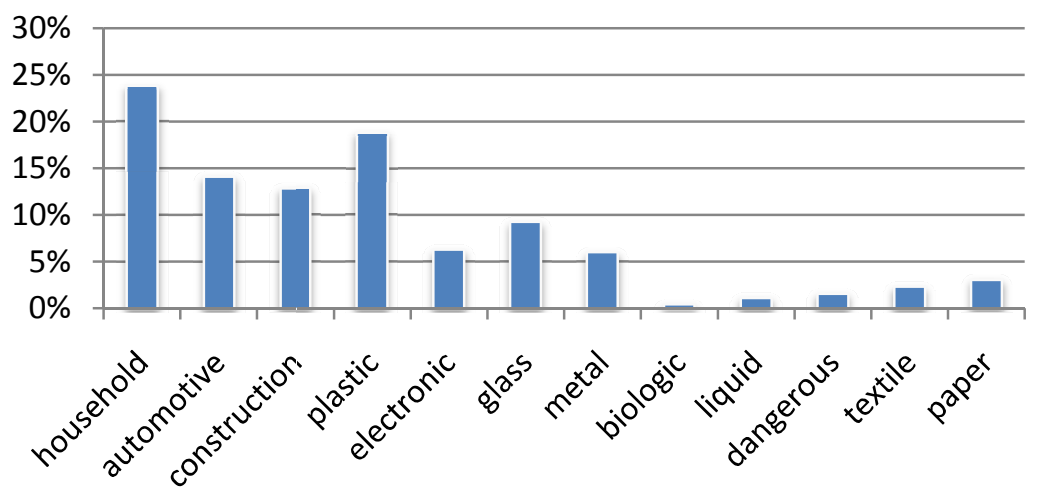

Fig. 6. Distribution of waste per type

\section{Conclusion}

The ZmapujTo project has been launched a year ago. During its existence over 1700 illegal dump sites in the Czech Republic have been reported and mapped in the system. The crowd-sourcing approach and the developed mobile application for reporting and mapping facilitated the dedection of illegal dumps. Furthermore the public awareness was heavily increased. 29 pilot municipalities of the Czech Republic are already involved in this project and over 400 illegal dump sites have been disposed since the last year. [10]

We believe that the ZmapujTo project is vital and has a great potential in the future also taking into account its possible usage in neighbouring States of the Czech Republic, taking advantage of the INSPIRE GEOPORTAL ${ }^{10}$. We are looking forward to others users interested in getting involved either local governments or organizations responsible for elimination of illegal dump sites.

\section{References}

1. Hanfman, E.: A Comprehensive Assessment of Illegal Waste Dumping. Water Health Educator (2009), http://www. waterheal theducator.com/upload/Illegal\%20 Waste $\% 20$ Dumping $\% 20$ Article.pdf

2. Europol. Europol warns of increase in illegal waste dumping (2011), https: / /www. europol . europa. eu/content/simplenews / europol-warns-increase-illegal-waste-dumping-1057

3. AnyJunk Fly Tipping Report 2012 (2012), http://www.anyjunk.co.uk/ fly-tipping-report-2012

10 http: //inspire-geoportal.ec.europa.eu/ 
4. Fechtnerová, A.: The issue of illegal dumping on land designated for forestry. Lesnická práce - časopis pro lesnickou vědu a praxi 3 (2011),

http: / /www. silvarium.cz/lesnicka-prace-c-3-11/problematikacernych-skladek-na-pozemcich-urcenych-k-plneni-funkci-lesa

5. Waste Management Information System of the Czech Republic (2013), http: / / www1 . cenia.cz/www/odpady/isoh

6. Morita, A., Takagishi, S.: GIS-based Support Systems for the Reduction of Illegal Dumping. In: Proceedings 22nd Annual Esri International User Conference-Exploring the New World of GIS!, San Diego, California, U.S.A, July 8-12 (2002), http: / /proceedings .esri.com/library/userconf /proc02 /pap1172 / p1172.htm

7. Tasaki, T., Kawahata, T., Osako, M., Matsui, Y., Takagishi, S., Morita, A., Akishima, S.: A GIS-based zoning of illegal dumping potential for efficient surveillance. Waste Management 27, 256-267 (2007)

8. Ichinose, D., Yamamot, M.: On the relationship between the provision of waste management service and illegal dumping. Resource and Energy Economics 33, 79-93 (2011)

9. Illegal Dumping project (2013), http: / / www.hccrems.com.au/Programs / Environmental-Compliance/Sub-projects/Illegal-Dumping .aspx Šauer, P., et al.: Visegrad Countries: Environmental Problems and Policies. Published by CENIA, Prague (2013)

10. Kubásek, M., Hřebíček, J.: Crowdsource Approach for Mapping of Illegal Dumps in the Czech Republic. International Journal of Spatial Data Infrastructures Research (to be pubished 2013) 